\title{
Development of Silicon Based Ceramic Matrix Composite Brake Material for Military Aircrafts
}

\author{
Mr. Sourabh S. Borchate ${ }^{1}$, Dr. D.D. Shukla ${ }^{2}$, Dr. Sachin K. Patil ${ }^{3}$, \\ ${ }^{1}$ PhD Scholar, Department of Mechanical and Automation Engineering, Amity University, Jaipur, Rajasthan, \\ India, 302001 \\ ${ }^{2}$ Professor and Director, Amity School of Engineering and Technology, Amity University, Jaipur, Rajasthan, \\ India, 302001. \\ ${ }^{3}$ Assistant Professor, Department of Mechanical Engineering, Rajarambapu Institute of Technology, \\ Rajaramnagar, Islampur, Maharashtra, India 415414
}

\begin{abstract}
Literature Review:
Shangwu Fan1, Chuan Yang, Liuyang He, Yong Du, Walter Krenkel, Peter Greil and Nahum Travitzky.

Carbon fibre reinforced silicon carbide $(\mathrm{C} / \mathrm{SiC})$ brake materials are new highly competitive brake materials. They possess a series of outstanding advantages such as high strength, low density, good high temperature resistance, excellent friction properties, low wear rate and long life. Up to now, it has been equipped in some type of aircraft, and high end cars. The paper presents a brief state of the art of $\mathrm{C} / \mathrm{SiC}$ brake materials. The attention is focused on manufacturing process, properties and wear mechanisms of $\mathrm{C} / \mathrm{SiC}$ aircraft brake materials, as well as progress and future of the aircraft brake materials.
\end{abstract}

\section{T.R. Prabhu:}

Metal matrix hybrid composites are usually preferred for high energy aircraft (1-10 MJ) brake pads (HEABP) applications. The report focuses mainly on the evaluation of the wear and braking performance of the composite for the military aircraft applications. In this paper, the design and processing of a typical HEABP composite have been discussed in detail. The airworthiness qualification tests for the HEABP and the brake units are outlined with details. Also, brake testing parameters calculations derived from the typical aircraft data are presented for both the laboratory and full scale dynamometer tests. A case study of Fe-Si3N4- graphite composite pads is presented to exemplify the steps involved in the design, development, and airworthiness certification of HEABPs for the $8 \mathrm{MJ}$ energy military aircraft. From the microstructure and wear surface morphology analysis and the results of brake performance parameters, functional tests and aircraft trials, it is concluded that the Fe-Si3N4- graphite composite has a minimum life of 200 normal energy landings with excellent braking performances.

\section{Yu Shu, Chen Jie, Huang Qizhong, Xiong Xiang, Chang Tong and Li Yunping:}

This paper describes the tribological properties of carbon/carbon composites used as braking materials under various braking speeds, in which the materials with three kinds of microstructures were used: rough lamina (sample A), smooth lamina (sample B), and the mixture of rough lamina and smooth lamina (sample C), respectively. Friction tests were carried out through a laboratory dynamometer. Polarized optical microscopy $(\mathrm{OM})$ and scanning electron microscopy (SEM) were used to characterize the microstructure and worn surface. Results indicated that the friction coefficient of sample A reached a peak value at braking speed lower than that in both sample B and sample C. However, when the friction coefficients reached to the peak values the temperature inside the worn surface was observed to be approximately 250_C for all of the samples. The weight losses in all of the samples were observed to increase with increasing braking speed; however, the oxidation losses at speed of $28 \mathrm{~m} \_\mathrm{s} \_1$ are higher than that of $30 \mathrm{~m} \_\mathrm{s} \_1$ for all of the samples.

\section{T.L. Ho, F.E. Kennedy, and M.B. Peterson:}

This report describes a test program which was carried out to evaluate several proposed design modifications and several new high-temperature friction materials for use in aircraft disk brakes. The evaluation program was carried out on a specially built test apparatus utilizing a disk brake and wheel half from a small jet aircraft. The apparatus enabled control of brake pressure, velocity and braking time. Tests were run under both constant and variable velocity conditions and covered a kinetic energy range similar to that encountered in aircraft brake service. The results of the design evaluation program showed that some improvement in brake performance can be realized by making design changes in the components of the brake containing friction material. The improvement is not too significant, however. The materials evaluation showed that two newly developed friction materials show potential for use in aircraft disk brakes. One of the materials is a nickel-based 
sintered composite, while the other is a molybdenum-based material. Both materials show much lower wear rates than conventional copper-based materials and are better able to withstand the high temperatures encountered during braking. Additional materials improvement is necessary, however, since both materials show a significant negative slope of the friction-velocity curve at low velocities.

\section{S. Vats, Heena, A. Katyal, H. Kamal S.K. Chaturvedi, V.K. Patidar:}

A brake is a device for slowing or stopping the motion of a machine or vehicle, or restraining it from starting to move again. Aircraft brakes are disc and are usually hydraulically or pneumatically operated. These brakes, for land based aircraft, are exclusively positioned on the main wheels although there have been some aircrafts over the years which have also had nose wheel brakes. A typical aircraft braking system uses links and cables that port some of the aircraft hydraulic pressure to the brakes after going through a valve that meters the amount of pressure. Operation of the brakes has evolved from a single lever applying all brakes symmetrically, to heel operated pedals, to toe operated brake controls incorporated into the rudder pedals. The foot operated controls has resulted in the ability to apply left or right brakes independently allowing use of differential braking system to steer the aircraft during ground operations and to maintain directional control during that portion of the take-off or landing roll when the airspeed is too low for the aerodynamic controls to be effective. This paper also focuses on preliminary study of different types of aircraft braking which includes: Aircraft disc brakes in the landing gear, used to brake the wheels while touching the ground; Thrust reversers, that allow thrust from the engines to be used to slow the aircraft. Air brakes, dedicated flight control surfaces that work by increasing drag; Drogue Parachutes, used by several former and current military and civilian aircraft. The study carried out in this paper is therefore, the primary study of Aircraft Braking system; its various types and their. Vats et al 192 applications in different aircrafts depending upon the type of flight and the landing conditions available. Also, emphasis is laid on the fail-safe technology which includes a particular device or a system that prevents or mitigates unsafe consequences of the system's failure; that is, if and when a "fail-safe" system "fails", it is "safe" or at least no less safe than when it is operating correctly. The study regarding this technology will be useful for projects related to Aircraft Braking system applications in the sector where drogue parachute technology may be taken into consideration as a Fail-Safe system against a conventional braking system or a simple parachute (which could get caught in itself while unfolding and fail to inflate properly, thus not slowing the falling object as much as it should).

\section{Zverev and S. S. Kokonin:}

An attempt is made in this book to summarize the experience in the design and analysis of aircraft wheels and brakes, brake systems, brake control systems, and antiskid systems. We examine some questions of the static and fatigue life, brake dynamics, techniques $\mathrm{f}$ o $\mathrm{r}$ increasing brake energy absorption capacity, aid design of the basic antiskid system elements. The book is intended for personnel in the aircraft industry and organizations operating aircraft.

\section{Jared Feist:}

Brakes are a principal control system that is standard on all passenger vehicles. Braking standards and requirements are developed and governed by the National Highway Traffic Safety Administration in collaboration with the Society of Automotive Engineers. Brakes are designed with performance, comfort, and manufacturability in mind, but still must adhere to NHTSA regulations. This project presents finite element model simulations focusing on the performance of different types of disc brake pads under dry sliding friction (thermal effects omitted). While it is recognized that thermal effects are unavoidable during braking they are outside the scope of this project. The finite element model is developed in ABAQUS/CAE using the general brake disc and pad geometry from a common passenger vehicle. The finite element analysis is simplified by utilizing the inherent symmetry of a disc brake and applying symmetric boundary conditions. Four different brake pad materials were analysed to predict braking performance. The finite element analysis results presented herein illustrate that all brake pad materials very closely meet the $2.4 \mathrm{~m} / \mathrm{s} 2$ baseline brake performance, the ceramic brake pad material demonstrated the highest average deceleration at $2.325 \mathrm{~m} / \mathrm{s} 2$. Utilizing the findings from this analysis, along with industry standards for measuring performance of brake pad materials; such as heat absorption, vibration damping, wear rate, and price, the appropriate brake pads can be chosen for individual applications.

\section{Jean-Jacques Sinou, Olivier Dereure:}

Friction induced vibrations are a major concern in a wide variety of mechanical systems. This is especially the case in aircraft braking systems where the problem of unstable vibrations in disk brakes has been studied by a number of researchers. Solving potential vibration problems requires experimental and theoretical approaches. A nonlinear model for the analysis of mode aircraft brake whirl is presented and developed based 
on experimental observations. The non-linear contact between the rotors and the stators, and mechanisms between components of the brake system are considered. Stability is analysed by determining the eigenvalues of the Jacobian matrix of the linearized system at the equilibrium point. Linear stability theory is applied in order to determine the effect of system parameters on stability.

\section{Dr. Abd Rahim Abu Bakar:}

This paper presents wear prediction of friction material in a disc brake assembly. A new and unworn pair of brake pads is tested under different durations of brake application to establish wear on their surfaces. One of the wear models available in the literature is adopted and then modified to suit the current work. A detailed 3 dimensional finite element (FE) model of a real disc brake is developed considering the real surface topography of the friction material. Confirmation of the adopted model is made between predicted and measured static contact pressure distribution and surface topography of the friction material. Predicted unstable frequencies and experimental squeal frequencies are shown to be in fairly good agreement.

\section{Mohammad Asif, K. Chandra and P.S. Misra:}

A new $\mathrm{P} / \mathrm{M}$ route based hot powder pre-form forging process has been evolved to develop high density brake materials for heavy duty applications. Number of iron based MMC's so developed offer better characteristics for braking applications in comparison to the materials developed through conventional $\mathrm{P} / \mathrm{M}$ route based on high pressure compaction and pressure sintering. The process so developed in the present investigations is much simpler and easy to adopt by existing P/M industries. Hot powder pre-form forging technique for making heavy duty brake pads offers better opportunity for pore free material with better bonding between various metallic and non-metallic constituents. After conducting an initial characterization such as hardness, density and Pin-on Disc tests, the samples were tested for high energy $(32,933 \mathrm{kgfm})$ on Sub-scale dynamometer under Rejected Take Off conditions. The results have also been compared with respect to brake pads employed in heavy duty Military aircraft tested under identical laboratory conditions. The present work indicates that the newly developed materials compare better than the one being currently employed in heavy duty aircraft. The reasons for better performance are improved processing technique and resulting higher levels of density and improved binding of the product.

\section{M.A. Maleque and U. Abdullahi:}

Research works are being done to substitute heavy material with a suitable lighter weight and cheaper material which has better properties for this particular application. Processing route plays a significant role in developing the material for any application with effective cost and environmental factors and careful selection of processing route is especially very important for brake disc material. In this paper, a comprehensive review has been done on material and processing route in view of selecting alternative lightweight and cheaper materials for aircraft brake disc application. The advantages and disadvantages between aluminium metal matrix composite and other materials as well as the advantages of powder metallurgy route with other processes are presented for better understanding of the materials and process selection. Finally, emphasis has given on lightweight and cheaper carbon nanotube aluminium matrix (CNT-Al) nano-composite material with specific processing route as a case study. This is mainly based on material selection using material selection process which showed CNT-Al as an excellent candidate material for brake disc application.

\section{Marc A. Stelmack, Stephen M. Batill:}

A Multidisciplinary Design Optimization framework called Concurrent Subspace Design (CSD) has been applied to the design of an aircraft brake assembly. This application entailed an interactive implementation of CSD in which design information was obtained using existing industrial analysis software. The optimization problem statement in this study included a number of performance requirements associated with a brake that has been produced for a commercial aircraft. The results indicated that the CSD framework was able to efficiently identify improved designs which met all the constraints imposed on the problem. The designs do not represent practical alternatives, however, because considerations related to production and maintenance costs, which are paramount in industry, were not incorporated into the optimization problem statement.

\section{Introduction}

A ceramic material is an inorganic and non-metallic compound, often made up of metallic and nonmetallic bonding. These ionic compounds form positively charges cations bonding to negatively charged anions. Historically ceramics didn't have many mechanical applications due to the properties of the material. Ceramics are very brittle, have little energy absorbs ion and cannot undergo plastic deformation. They have a resistance to high temperature, and can withstand high compressive loads. For example a porcelain ceramic can withstand a compressive load ten times greater than its tensile strength. 
The purpose of ceramic matrix composites is to allow a greater amount of mechanical applications by reducing the materials brittleness. A CMC material is made up of a monolithic ceramic reinforced with composite fibers to decrease the crack propagation in the material. This reinforced material can be used in many different applications, since it is no longer limited by its fragile properties.

There are many types of CMC materials that contain different mechanical and chemical properties. Some are designed for increased strength, toughness, creep resistance, while others can have greater thermal and electrical properties. The resulting properties are dependent on what fibers are added to the ceramic matrix, and what how the material is manufactured into its shape.

Disc brakes are typically made out of grey cast iron. This material is has high tensile strength and can withstand a high temperature before failing. In high performance vehicles the amount of heat generated by friction when braking can be too great so the brakes fail or must be changed often. The failure is due to thermally induced fractures. Also these brakes can be heavy and susceptible to corrosion, which cause failure.

Other composites have been tested such as Metal Matrix Composite, and Carbon Carbon Composites. The challenges with these materials are the ability to dissipate heat caused by friction isn't optimal at high enough temperatures. A typical grey cast iron disc brake can withstand a surface heat of $400{ }^{\circ} \mathrm{C}$ before failure occurs.

\section{Proposed Work}

With high thermal properties of ceramics, combined with fiber enhanced strength, ceramics are no longer limited by their fragile mechanical properties. They have high durability, lower density and corrosion resistance that expand the mechanical applications. With new efficient manufacturing techniques CMC's will continue to be used in high performance heat systems while replacing traditional metal components.

Silicon-infiltrated carbon-carbon composite is used for high performance "ceramic" brake discs, as it is able to withstand extreme temperatures. The silicon reacts with the graphite in the carbon-carbon composite to become carbon-fiber-reinforced silicon carbide $(\mathrm{C} / \mathrm{SiC})$. These discs are used on some road-going sports cars, supercars, as well as other performance cars. Silicon carbide is also used in a sintered form for diesel particulate filters. $\mathrm{SiC}$ is also used as an oil additive to reduce friction, emissions, and harmonics.

In military aircraft brakes we can used silicon based ceramic matrix composites brake materials to increases performance. My proposed work will be focus on development of new silicon based ceramic matrix composite brake materials for military aircrafts.

\section{References}

[1]. Shangwu Fan, Chuan Yang, Liuyang He, Yong Du, Walter Krenkel, Peter Greil, and Nahum Travitzky. "Progress of ceramic matrix composites brake materials for aircraft application”, Rev. Adv. Mater. Sci. 44 (2016) 313-325.

[2]. T.R. Prabhu. "Airworthiness Certification of Fe-Si3N4-graphite Brake Composites for Military Aircraft", CEMILAC, Defence R and D Organization, India. Tribology in Industry Vol. 37, No. 4 (2015) 491-499.

[3]. Yu Shu, Chen Jie, Huang Qizhong, Xiong Xiang, Chang Tong and Li Yunping, "Effect of Braking Speeds on the Tribological Properties of Carbon/Carbon Composites", Materials Transactions, Vol. 51, No. 5 (2010) pp. 1038 to 1043.

[4]. T.L. Ho, F.E. Kennedy, and M.B. Peterson, "Evaluation of materials and design modifications for aircraft brakes", National technical information service, U.S. department of commerce Springfield, VA. 22161, NASA CR 134896

[5]. S. Vats, Heena, A. Katyal, H. Kamal, S.K. Chaturvedi, V.K. Patidar, "Preliminary Study of Aircraft Braking System with Emphasis on Fail-safe Technology", Advances in Aerospace Science and Applications, ISSN 2277-3223 Volume 3, Number 3 (2013), pp. 191-198.

[6]. I. I. Zverev and S. S. Kokorin, "Design of aircraft wheels and brake systems", NASA technical translation, National aeronautics and space administration, Washington, d. c. 20546 June 1975.

[7]. Jared Feist, "Finite Element Modelling of Brake Pad Materials Performance", Rensselaer Polytechnic Institute Hartford, Connecticut, December 2014.

[8]. Jean-Jacques Sinou, Olivier Dereure, Guy-Bernard Mazet, Fabrice Thouverez, Louis Jezequel, "Friction-induced vibration for an aircraft brake system Part 1: Experimental approach and stability analysis", International Journal of Mechanical Sciences, Volume 48, Issue 5, May 2006, Pages 536-554

[9]. Dr. Abd Rahim Abu Bakar, "Wear prediction of friction material and brake squeal using the finite element method", Elsevier Editorial System for Wear, Manuscript Number: IH-4139R1.

[10]. Mohammad Asif, K. Chandra and P.S. Misra, "Development of Iron Based Brake Friction MMC Used for Military Aircraft Application by A New P/M Route", Journal of Minerals \& Materials Characterization \& Engineering, 2011, Vol. 10, No.8, pp.693705 .

[11]. M.A. Maleque and U. Abdullahi, "Materials and processing route for aircraft brake system", International Journal of Mechanical and Materials Engineering (IJMME), Vol. 8 (2013), No. 1, Pages: 14-20.

[12]. Marc A. Stelmack, Stephen M. Batill, "Design of an aircraft brake component using an interactive multidisciplinary design optimization framework", American Institute of Aeronautics and Astronautics. 